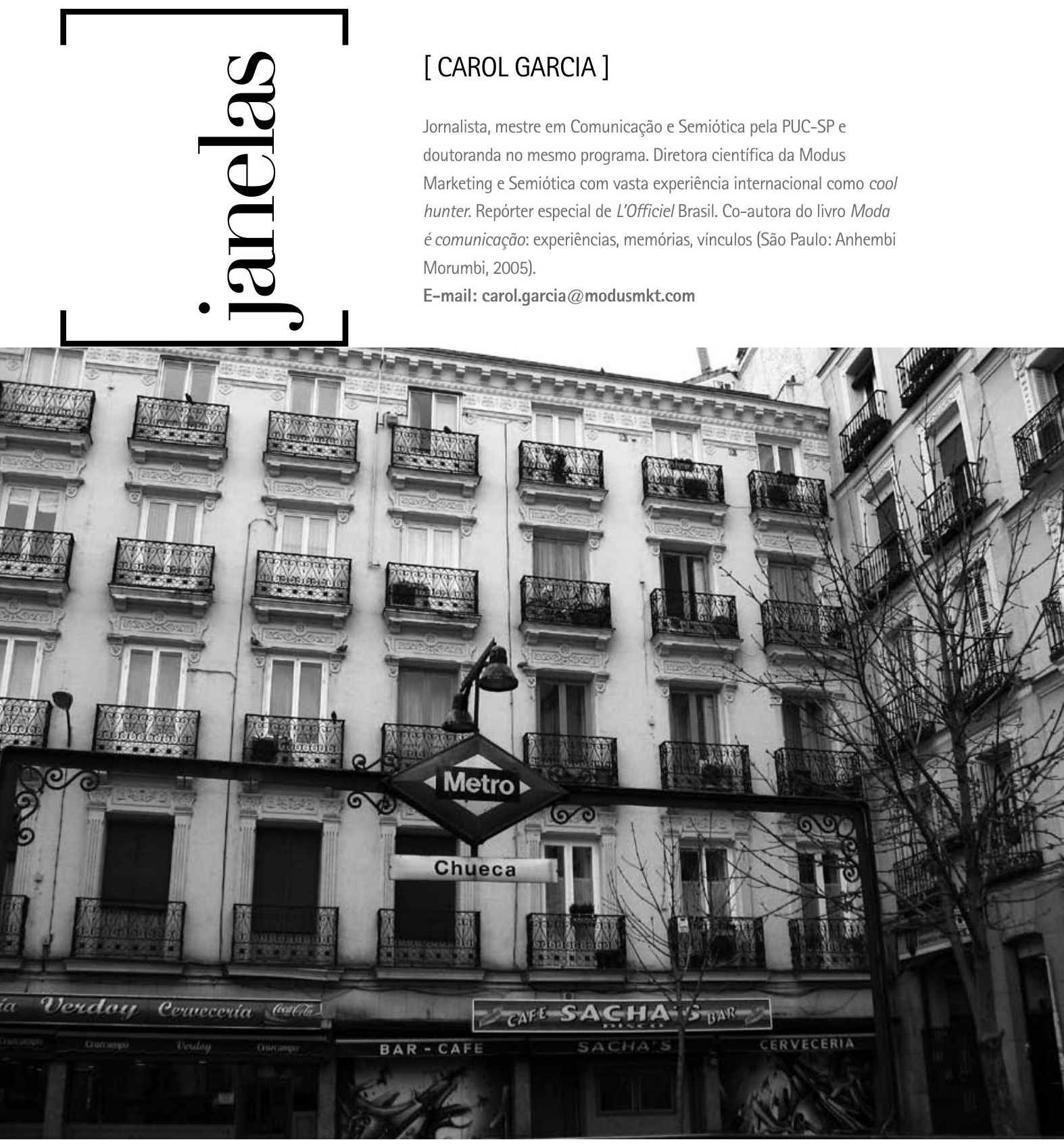

Estação Chueca do metrô

Em 1591, num tratado intitulado Sobre os vínculos em geral, o filósofo italiano Giordano Bruno (1548-1600) já apontava que o ambiente é parcialmente responsável pela natureza da ligação entre dois ou mais elementos. A cidade de Madri, na Espanha, parece ter entendido isso muito bem, criando processos de interação social a partir dos distintos sistemas de vínculos estabelecidos entre seus moradores. Mas como são elaborados esses vínculos comunicativos? Design gráfico, visual merchandising, gastronomia e moda, juntos, formam a razão de ser fraternal de um bairro colorido com os tons do arco-íris, a Chueca. Cercada pelas ruas Barquillo, Hortaleza, Gran Vía e Alfonso $\mathrm{Vl}$, a região é famosa mundo afora. Afinal, foi lá que surgiu, nos anos 1980, o fenômeno conhecido como La Movida, agito pós-franquista que transformou a então sisuda e cinzenta Madri com as cores de Agatha Ruiz de La Prada, a musicalidade de Miguel Bosé e a ironia de Pedro Almodóvar.

Posteriormente, a zona transformou-se no catalisador da indústria criativa, recheando as antigas mansões com produtos de novos designers, chefs e visionários em geral, além de atrair a comunidade gay feito ímã. 0 resultado? Algumas das lojas mais avant-garde da capital espanhola. Eu, particularmente, adoro a Óptica Toscana (Hortaleza, 70, www.opticatoscana.com), instalada em antigo empório de produtos agrícolas e venda de sementes, bem em frente de uma butique de underwear masculino para o público metrossexual, que leva o singelo nome de Ana Millán. 
A proprietária da Toscana, Carmen Dominguez, garimpa designers de óculos no mundo inteiro, com especial atração pela Itália. 0 resultado são armações de estética impar e classuda - daquelas que fariam marcas tradicionais, como Vuarnet ou Ray-Ban, rosnarem de inveja -, apresentadas em caixas de sementes! Já a vizinha de frente oferece todos os apetrechos para animar o mercado de roupa interior, incluindo curiosas cuecas com shape progressista (recheadas na frente e no verso) para ampliar e definir curvas estratégicas. Tudo isso sem perder a aparência de loja do interior: graças a uma vitrina em que o visual merchandising de outrora transforma o que poderia ser agressivo numa expressão de sexualidade divertidamente ingênua. Bem distinto dos muitos sex shops da área, cujo mote é, precisamente, exacerbar o discurso de uma estética fetichista.

\section{A favorita}

Ana Millán fica na esquina de minha viela predileta, batizada em homenagem ao grande conquistador espanhol Hernán Cortés. É nessa ruazinha estreita que se localiza a melhor livraria da cidade, a Panta Rhei (Hernán Cortés, 7, www.panta-rhei.es). Ali descobri o designer gráfico Juanjo Sáez, autor do ótimo livro-HO El arte: conversaciones imaginarias con mi madre (Reservoir Books, 2006), além de uma galeria de ilustração fantástica e muitos, mas muitos mesmo, livros de moda. Dizem as más línguas que eles aceitam pedidos pela internet, porém o que eu gosto de verdade é de ir lá, folhear e ler sem pressa. Depois estico até a vizinha Lotta Vintage (Hernán Cortéz, 9), um espaço que adorava o Abba antes mesmo do sucesso da canção, do musical e do filme Mamma mia. Explico: na Lotta só entram designers nórdicos, em versão século passado e ao som das bandas suecas que a gente morre de vergonha de amar.

Em nossa defesa, vem o biólogo norte-americano Harry Harlow. É ele quem dá uma contribuição contundente ao entendimento da natureza indócil dos vínculos comunicativos quando observa que essa ligação inicia-se a partir da mais tenra infância'.

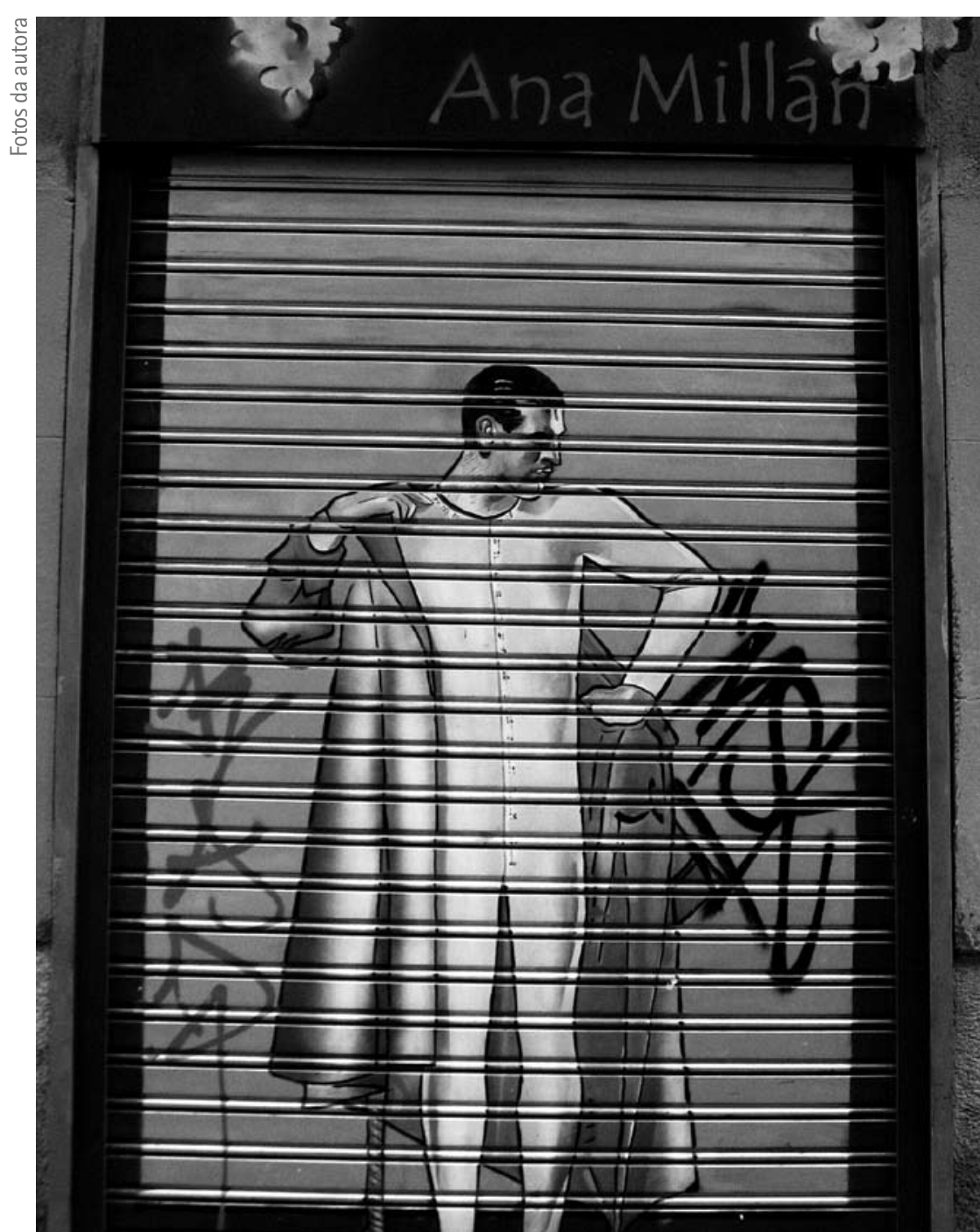


